\title{
Nutrition problems specific to the adult Mexican population: the healthy eating plate as an intervention in the diets of older adults in Mexico, with an example
}

\begin{abstract}
This article explains the use of the plato del bien comer (healthy eating plate) as a basic strategy for intervention in the diets of Mexican adults, including seniors, with diabetes. The healthy eating plate has the advantage of clearly representing the contents of a balanced meal, which might be not clear in other diagrams such as the food pyramid. This article provides an example of the healthy eating plate from a manual published by the National Institute of Nutrition in Mexico for people with diabetes. The manual respects the particularity of Mexican food by incorporating the tastes and varieties of various regional foods into its menus.
\end{abstract}

Keywords: nutrition, diabetes, self-care.
Volume 3 Issue 3 - 2018

\section{José Enrique Gómez-Álvarez \\ Centro de Investigación Social Avanzada, Santiago de Querétaro,} México.

Correspondence: Jose Enrique Gomez Alvarez, Centro de Investigación Social Avanzada, Santiago de Querétaro, México. Tel +5562702 I 0, Email jegomezalvarez@yahoo.com

Received: May 31, 2018 | Published: June 27, 2018

\section{Introduction}

Mexico ranks first in the world in childhood obesity and second in adult obesity. ${ }^{1}$ Additionally there appears to be a correlation between obesity and an increase in diabetes among the population. This disease has particularly become an epidemic among older adults in Mexico. ${ }^{2}$

Due to the nature of type 2 diabetes, this disease tends to develop in adulthood and in many cases affects older adults. Diabetes therefore often presents itself in adults along with other comorbidities, such as hypertension, osteoporosis, or stages of Parkinson's disease. Nonpharmacological treatments, including proper nutrition, are part of a strategy for treating diabetes that includes awareness, prevention, self-evaluation, and self-care.

An effective strategy for achieving proper nutrition is incorporating all the food groups into one's diet so that each meal contains food from all the nutritional groups. In Mexico, the standard of the plato del bien comer (healthy eating plate) is used (Figure 1).

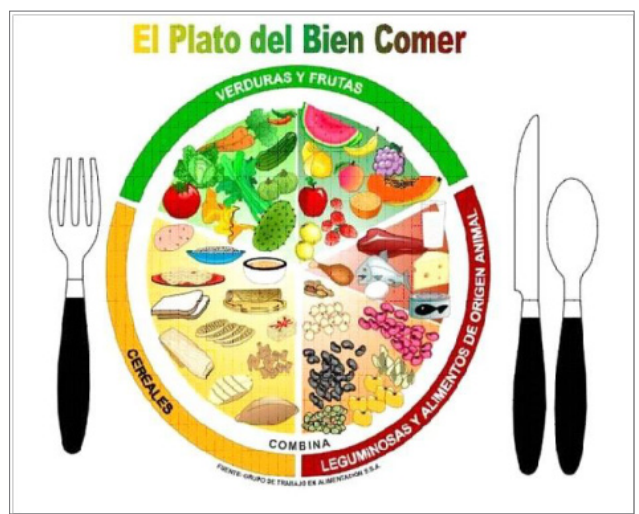

Figure I Healthy Eating Plate.

[The healthy eating plate fruits and vegetables grains legumes and foods of animal origin combine]

Source Secretaría de Salud, Mexico 3.I.
The intuitive idea presented by the healthy eating plate, unlike the nutritional pyramid, ${ }^{3}$ is that no one type of food is more important than another. The healthy eating plate indicates that what is important is variety in one's diet and the inclusion of different types of foods in each meal of the day. By contrast, the food pyramid suggests that there is a hierarchy of better and worse foods.

Types of food are divided into groups in the healthy eating plate. As the Official Standard for Control and Prevention of Diabetes makes clear, there is no ranking of food types (Norma, 8.2.1.3.3).

The food groups are classified in a summary manner as follows: I. fruits and vegetables; II. grains, legumes, cereals, and tubers; III. foods of animal origin; and IV. fats, sugars, and oils. Foods may also be classified into the following more specific categories: I. cereals and tubers; II. legumes; III. vegetables; IV. fruits; V. foods of animal origin, cheese, and eggs; VI. milk; VII. lipids; and VII. sugars.

The emphasis of the healthy eating plate is not the groups as such, but the balancing of food groups. One of the advantages of using this image to encourage proper nutrition is that older adults can visualize food that it is well known to them, such as tortilla or well-known regional fruits.

In nutrition, self-care entails learning to cook or access foods that are adequate to one's needs. Two objectives of offering a manual of menus are to help adults enjoy eating better and, if they are able to, enjoy preparing healthy meals. To achieve these objectives, the menus provided must use foods that adults can easily obtain in their surroundings, for example in a public market. The meals must also not require too much time or effort to cook. The manual Menús para pacientes con diabetes (2014) is recommended in particular. In addition to satisfying the criteria indicated above, the manual contains up-to-date information and considers the distinct circumstances of adults living in Mexico. It also proposes a wider variety of meals than similar manuals and is published by the National Institute of Nutrition, which is undoubtedly the foremost authority on these topics in Mexico. 
Regarding menus, this manual has the advantage of allowing readers to prepare their menus in two ways. It includes one system of menus with calorie totals already established ${ }^{4}$ and another system for readers who wish to calculate their total calories themselves. ${ }^{2}$ The Official Mexican Standard for Treatment of Diabetes indicates that "The total energetic contribution must be adjusted, to maintain a recommendable weight, avoiding diets with less than 1,200 dietary calories per day" (Norma, 8.2.1.3.5).

One's daily nutrients should consist of $20 \%$ proteins, $30 \%$ lipids, and $50 \%$ carbohydrates. In turn, the distribution of calories consumed in breakfast, lunch, and dinner should be $30 \%, 40 \%$, and $30 \%$, respectively. In light of these recommendations, the meals that are suggested in Menús para pacientes con diabetes contain the equivalent to $40 \%$ of one's required daily energy, or 480 dietary calories (Table 1).

In this menu, salt may be reduced or eliminated without any problem to accommodate hypertension patients. There are certain criteria that guide our nutritional choices. These include the environment that we live in, the variety of foods we desire to eat, or the number of dietary calories we aim to consume. It has been established that the average daily energy requirements in Mexico are 1600-1800 calories for women and 1800-2000 calories for men. ${ }^{5}$ All of the meals in the manual Menús para pacientes con diabetes are excellent for older adults that need to eat a variety of foods at a relatively low cost.

It is important to remember, however, that the appropriate diet for each person necessarily depends on their age, physical condition, physique, exercise habits, and any diseases they may have.

Table I An example of a meal with these characteristics 4 is the following

\begin{tabular}{ll}
\hline Dish & Ingredients for preparation \\
\hline Onion soup & I/4 cup onion \\
& I teaspoon wheat flour \\
& I teaspoon smooth unsalted margarine \\
Meat with vegetables & Broiled meat (60g) \\
& Carrots (I/4 cup) \\
& Chard (I cup) \\
& Oil (I teaspoon) \\
& Garlic (to taste) \\
& Pepper (to taste) \\
\hline
\end{tabular}

Table continuded

\begin{tabular}{ll}
\hline Dish & Ingredients for preparation \\
\hline Beans & Salt (a dash) \\
& Cooked Beans (1/2 cup) \\
& Onion (to taste) \\
& Salt (a dash) \\
Roll & I/3 piece \\
Water with orange & 2 cups \\
leaf & Orange leaves (to taste) \\
& Artificial sweetener (to taste) \\
Strawberries. & I cup \\
\hline
\end{tabular}

\section{Conclusion}

Because of its visual appearance and calculation of calories, the healthy eating plate is an especially helpful tool for motivating older adults to select the best food for themselves. In the case of Mexico, there are specific calorie requirements that each person must meet. The main goal of using the healthy eating plate to convey the importance of having variety in one's diet and eating balanced meals The healthy eating plate is used in Mexico as a visual aid in combination with a calorie counting strategy. In all cases, however, differences between individuals must be considered.

\section{Acknowledgements}

None.

\section{Conflict of interest}

The author does not have any conflicts of interest to declare.

\section{References}

1. Secretaría de Salud. Norma Oficial Mexicana NOM 015 SSA 21994 para la prevención, tratamiento y control de la diabetes. México. 1998.

2. Secretaría de Salud. Norma Oficial Mexicana NOM 030 SSA 21999 para la prevención, tratamiento y control de la hipertensión arterial. 1999.

3. Myers E. Notas de enfermería. 3rd ed. México, Mc Graw Hill; 2010.

4. Fomento de Nutrición y Salud AC. Menús para pacientes con diabetes. México. 2014.

5. Secretaría de Salud. Guía de alimentos para la población mexicana. México, Pressprinting; 2010. 